Robin F. Benus

Hermie J. Harmsen

Gjalt W. Welling

Rob Spanjersberg

Jan G. Zijlstra

John E. Degener

Tjip S. van der Werf

\title{
Impact of digestive and oropharyngeal decontamination on the intestinal microbiota in ICU patients
}

Received: 13 August 2009

Accepted: 14 January 2010

Published online: 16 March 2010

(C) The Author(s) 2010. This article is published with open access at

Springerlink.com

Electronic supplementary material

The online version of this article

(doi:10.1007/s00134-010-1826-4) contains supplementary material, which is available to authorized users.

R. F. Benus - H. J. Harmsen .

G. W. Welling · J. E. Degener

Department of Medical Microbiology, University Medical Centre Groningen, University of Groningen, Groningen, The Netherlands

R. F. Benus · R. Spanjersberg

J. G. Zijlstra

Department of Critical Care,

University Medical Centre Groningen,

University of Groningen, Groningen,

The Netherlands

R. F. Benus - T. S. van der Werf Infectious Diseases and Tuberculosis Service, Department of Internal Medicine, Pulmonary Diseases and Tuberculosis, University Medical Centre Groningen, University of Groningen, Groningen, The Netherlands
T. S. van der Werf (ه)

P.O. Box 30001, Hanzeplein 1,

AA11, room U3.105, 9700 RB Groningen,

The Netherlands

e-mail: t.s.van.der.werf@int.umcg.nl

Tel.: +31-50-3611501

Fax: +31-50-3619320

Abstract Purpose: Selective digestive microbial decontamination (SDD) is hypothesized to benefit patients in intensive care (ICU) by suppressing Gram-negative potential pathogens from the colon without affecting the anaerobic intestinal microbiota. The purpose of this study was to provide more insight to the effects of digestive tract and oropharyngeal decontamination on the intestinal microbiota by means of a prospective clinical trial in which faecal samples were collected from ICU patients for intestinal microbiota analysis. Methods: The faecal samples were collected from ICU patients enrolled in a multicentre trial to study the outcome of SDD and selective oral decontamination (SOD) in comparison with standard care (SC). Fluorescent in situ hybridization (FISH) was used to analyze the faecal microbiota. The numbers of bacteria from different bacterial groups were compared between the three regimens. Results: The total counts of bacteria per gram faeces did not differ between regimens. The $F$. prausnitzii group of bacteria, representing an important group among intestinal microbiota, was significantly reduced in the SDD regimen compared to the SC and SOD. The Enterobacteriaceae were significantly suppressed during SDD compared to both SOD and $\mathrm{SC}$; enterococci increased in SDD compared to both other regimens. Conclusions: The composition of the intestinal microbiota is importantly affected by SDD. The $F$. prausnitzii group was significantly suppressed during SDD. This group of microbiota is a predominant producer of butyrate, the main energy source for colonocytes. Reduction of this microbiota is an important tradeoff while reducing gram-negative bacteria by SDD.

Keywords Bacteria, anaerobic . Molecular diagnostic techniques . Prophylaxis, antibiotic . Critical care . Microbiota, faecal

\section{Introduction}

Selective (microbial) decontamination of the digestive tract (SDD), developed using immuno-compromised animal models $[1,2]$, was first clinically tested in severely immuno-compromised hemato-oncological patients and later applied to patients admitted to intensive care units (ICU) [3]. The concept of SDD is to selectively suppress potential pathogens, mostly Gram-negative bacteria, without disturbing the anaerobic intestinal microbiota. 
Oral, non-absorbable antibiotics were combined with prophylactic systemic antimicrobial treatment (3rd generation cephalosporins) during the first four days to eradicate potential pathogens. In order to protect the anaerobic microbiota, the use of antibiotics with antianaerobic activity was discouraged.

Earlier studies were flawed by design [3] or lacked statistical power to detect a survival advantage. Metaanalyses showed a significant survival advantage $[4,5]$ one did not [6]. Also single centre randomized trials evaluating SDD showed reduction in mortality [7,8].

A consistent finding across studies evaluating SDD in the ICU has been a reduction of the number of episodes of nosocomial infections-especially, of respiratory tract. As the prevention of ventilator-associated pneumonia (VAP) might play a dominant role in the mortality reduction of SDD, the oropharyngeal component of SDD, referred to as Selective Oropharyngeal Decontamination (SOD), has also been analysed in clinical trials [9]. Although a significant reduction in VAP was shown, historically no overall reduction in mortality by SOD [10] or non-selective oral decontamination [11] was observed.

A large multi-centre clinical trial of SOD and SDD was recently reported. In this trial both SDD and SOD showed a similar survival benefit compared to standard care (SC) [12]. As an adjunct to this study we investigated the impact of SOD and SDD regimes on the intestinal microbiota compared to SC.

The intestinal microbiota is a complex ecosystem which comprises more than $10^{11}$ bacteria per gram of faeces and more than 400 different species [13]. Some of the intestinal microbiota are beneficial and ways to promote their growth have been investigated [14]. With the use of SDD, the intestinal microbiota is believed to protect the human host by preventing increased colonisation with potential pathogens [15], mostly anaerobic bacteria that are difficult to isolate and identify by classical culture techniques. Quantification of the anaerobic microbiota based on culture methods is unreliable: selective media introduce bias; and many genera cannot be cultured in vitro. Molecular methods, such as fluorescent in situ hybridisation (FISH), yield absolute numbers of microorganisms $[16,17]$ instead of colony-forming units, which is the quantitative read-out of culture.

In the present study we evaluate, for the first time with molecular methods, the impact of SDD and SOD on the intestinal microbiota compared to SC in subjects admitted to ICU. We tested the hypothesis that SDD (or SOD) may execute its claimed beneficial effects by leaving the anaerobic intestinal microbiota unaffected.

\section{Patients and methods}

All patients consecutively admitted to the Medical ICU in our hospital, and that were evaluated within the framework of the Dutch multi-centre SDD-SOD study [12], were eligible. In this SDD-SOD study, participating centres followed three different regimens of treatment in their ICUs in a non-blinded random sequence:

1. SC: no prophylactic antimicrobials, no restrictions in the antibiotics used

2. SOD: prophylactic topical oropharyngeal antimicrobials, no restrictions in the antibiotics used.

3. SDD: prophylactic topical oropharyngeal and gastrointestinal antimicrobials, with the addition of intravenous cefotaxime during the first four days. Selective use of antimicrobials was encouraged to avoid interference with the intestinal microbiota, in accordance with the concept of colonisation resistance.

The sequence of these courses allocated to our hospital was SC-SOD-SDD. For details of the trial and the antibiotic regimens used, we refer to the original article [12]. All included patients were scored for their severity of disease with the APACHE II classification system [18]. Other parameters that were recorded are demographics (age, gender etc.), concomitant diseases and the use of all antimicrobial products including the antimicrobials used for the prophylactic protocols (SOD and SDD).

During all three consecutive trial periods, faecal samples were collected from the patients that produced faeces spontaneously or with the use of laxatives as on clinical indication alone. For every patient, only the first sample faecal that was passed after at least three days of period-specific treatment by patients on mechanical ventilation was used in order to avoid skewing of data (see Fig. 1).

For the multi-centre SOD-SDD study, a waiver from informed consent was provided by local and National Ethics Review Boards, as not patients but rather different standards of treatment protocols were compared in a randomized fashion. Samples and data were analyzed anonymously.

\section{Materials and methods}

All fresh faecal samples were stored in a refrigerator and processed for analysis within $24 \mathrm{~h}$ after collection. The processing procedure was as follows: after homogenization, from each faecal sample $1.0 \mathrm{~g}$ (wet weight) was taken and diluted in PBS $(8 \mathrm{~g} / \mathrm{L} \mathrm{NaCl}, 0.2 \mathrm{~g} / \mathrm{L} \mathrm{KCl}$, $1.44 \mathrm{~g} / \mathrm{L} \mathrm{Na}_{2} \mathrm{HPO}_{4} \cdot 2 \mathrm{H}_{2} \mathrm{O}, 0.24 \mathrm{~g} / \mathrm{L} \mathrm{KH}_{2} \mathrm{PO}_{4}, \mathrm{pH}$ 7.4) $1: 4$ or 1:9 depending on faecal consistency. The faecal consistency was scaled on the Bristol Stool chart, where consistencies of stool type 1-6 were diluted 1:9, type 7 was diluted 1:4. These dilutions were processed for storage as described previously [19]. 
Fig. 1 Flow chart of patient selection

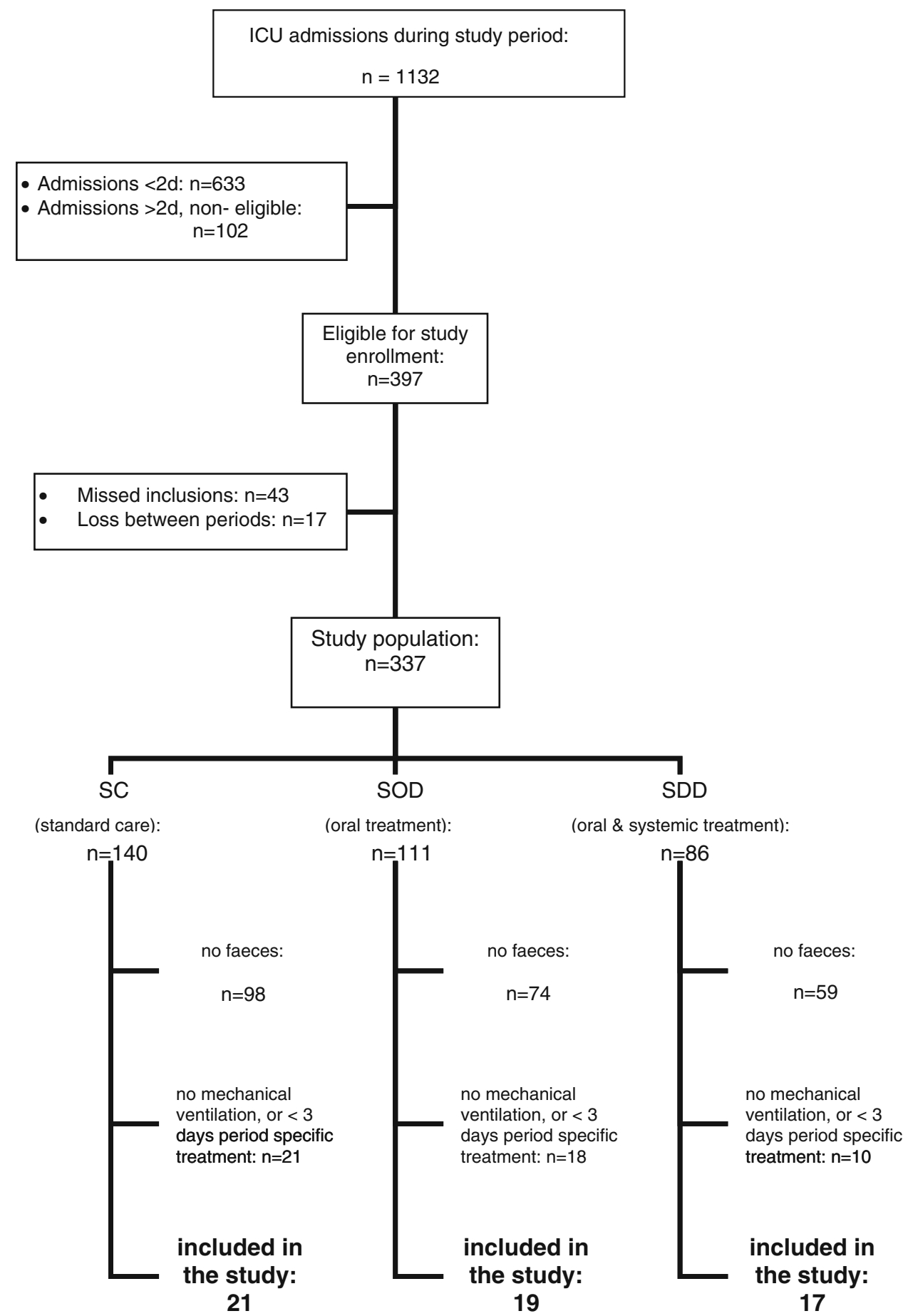

approximately $90 \%$ of the expected hybridisable total amount of bacteria (Eub338) [17]. Additional to the probe set for detection of the normal intestinal microbiota, three probes were used to enumerate groups of potential pathogens. These are the EC1531 [20] probe for the Enterobacteriaceae and the Enfl84 and Enfm93 [21] to detect enterococci. 
Table 1 Probes used for the detection of the intestinal microbiota

\begin{tabular}{|c|c|c|}
\hline Target & Probe & Sequence \\
\hline Total bacteria & EUB338 & 5'GCTGCCTCCCGTAGGAGT \\
\hline Bacteroides/Prevotella & Bac303 & 5'CCAATGTGGGGGACCTT \\
\hline E. rectale/Blautia coccoides & Erec482 & 5'GCTTCTTAGTCA(G/A)GTACCG \\
\hline$F$. prausnitzii-group & Fprau645 & 5'CCTCTGCACTACTCAAGAAAAAC \\
\hline Atopobium-group & Ato291 & 5'GGTCGGTCTCTCAACCC \\
\hline Bifidobacteria & Bif164 & 5'CATCCGGCATTACCACCC \\
\hline \multirow[t]{2}{*}{ Ruminococci } & Rbro730 & 5'TAAAGCCCAGYAGGCCGC \\
\hline & Rfla729 & 5'AAAGCCCAGTAAGCCGCC \\
\hline \multirow[t]{2}{*}{ Roseburia cluster } & Rint623 & 5'TTCCAATGCAGTACCGGG \\
\hline & Rint helper & 5'GTTGAGCCCCGGGCTTT \\
\hline Enterobacteriaceae & EC1531 & 5'CACCGTAGTGCCTCGTCATCA \\
\hline Enterococcus faecalis & Enfl84 & 5'CCTCTTTCCAATTGAGTGCA \\
\hline Enterococcus faecium-group & Enfm93 & 5'GCCACTCCTCTTTTTCCGG \\
\hline
\end{tabular}

References to the probes can be found in the supplementary material

The fluorescent cells in the samples were counted using an automated microscope system [22]. The detection limit used with this method was $10^{6}$ cells/g of faeces.

After analysis of the FISH results, minimal inhibitory concentrations (MIC) to the SDD/SOD antibiotics of a type strain of $F$. prausnitzii were performed. The A2-165 strain of $F$. prausnitzii was cultured in an anaerobic cabinet on YCFA agar-plates. YCFA medium consisted of (per $100 \mathrm{ml}$ ): $1 \mathrm{~g}$ casitone, $0.25 \mathrm{~g}$ yeast extract, $0.4 \mathrm{~g}$ $\mathrm{NaHCO}_{3}, \quad 0.1 \mathrm{~g}$ cysteine, $0.045 \mathrm{~g} \mathrm{~K} \mathrm{~K}_{2} \mathrm{HPO}_{4}, 0.045 \mathrm{~g}$ $\mathrm{KH}_{2} \mathrm{PO}_{4}, 0.09 \mathrm{~g} \mathrm{NaCl}, 0.009 \mathrm{~g} \mathrm{MgSO}_{4} .7 \mathrm{H}_{2} \mathrm{O}, 0.009 \mathrm{~g}$ $\mathrm{CaCl}_{2}, 0.1 \mathrm{mg}$ resazurin, $1 \mathrm{mg}$ haemin, $1 \mu \mathrm{g}$ biotin, $1 \mu \mathrm{g}$ cobalamin, $3 \mu \mathrm{g} p$-aminobenzoic acid, $5 \mu \mathrm{g}$ folic acid and $15 \mu \mathrm{g}$ pyridoxamine. Final concentrations of short-chain fatty acids (SCFA) in the medium were $33 \mathrm{mM}$ acetate, $9 \mathrm{mM}$ propionate and $1 \mathrm{mM}$ each of isobutyrate, isovalerate and valerate.

The MIC tests were performed using E-test ${ }^{\circledR}$-strips containing tobramycin, colistin and cefotaxime, according to the instructions of the manufacturer (AB BIODISK, Solna, Sweden).

\section{Statistics}

The results were compared statistically between the three patient groups using SPSS ${ }^{\circledR} 16$ statistical analysis software. For the continuous variables age and APACHEscores, ANOVA analyses were performed, for nominal variables such as antibiotics use, a Chi-square cross tabulation with a Fisher's Exact test was used (see Table 2 for details).

The analysis of the numbers of bacteria was done with an ANOVA analysis after log-transformation to obtain a normal distribution. The normal distribution was checked with the Kolmogorov-Smirnoff test and by evaluation of P-P plots.

The numbers of enterococci however were still not normally distributed after log-transformation, therefore for these bacterial groups non-parametric tests (MWU) were performed.

\section{Results}

Patients: Figure 1 shows the flowchart of the patient sample selection. Faecal samples were collected for analysis from a total of 21 patients in the SC regimen, 19 patients in the SOD regimen and 17 patients in the SDD regimen.

The age distribution of patients did not differ significantly between the three study episodes; in the SC group, the mean age was 59.8, in the SOD group 63.7 and in the SDD group 56.7.

APACHE-II scores were also similar between groups: 14.3, 15.4 and 16.2 for the SC, SOD and SDD groups, respectively. The APACHE predicted (adjusted) death rate was higher in both the SOD and SDD regimen groups. These differences were not statistically significant. Furthermore enteral tube feeding and gastric retention did not differ statistically significantly between the three regimen groups, see table 2 for details.

Except for the use of cephalosporins (which are a part of the SDD regimen) the use of antibiotics did not differ significantly between the regimens. Because no statistical difference in the characteristics of the population was found, no further multivariate analysis was performed.

No significant impact of SDD was observed on the total number of bacteria of the colonic microbiota (Table 3). There is, however, a significant difference in the composition of the microbiota of the different regimens. Some differences are seen in the bacterial groups between the analysed regimens, but the numbers of the $F$. prausnitzii group in the SDD-regimen are significantly lower compared to both Standard Care and the SOD regimen. The Eubacterium rectale group shows lower numbers of bacteria in the SDD regimen compared to the SC regimen. A 
Table 2 Characteristics of the patient population

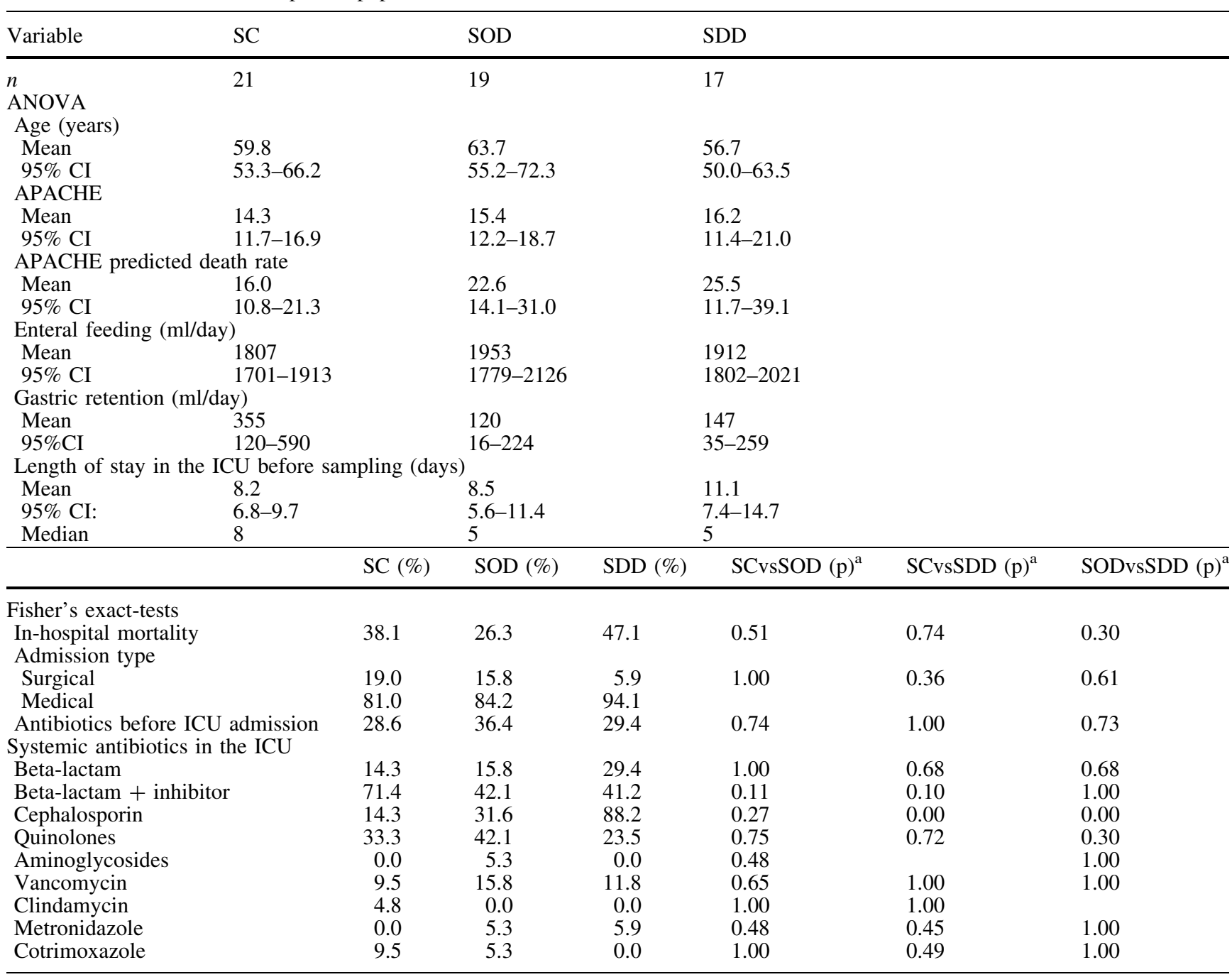

a Fisher's exact-test

subgroup of $E$. rectale-the Roseburia intestinalis group-also shows lower numbers in the SDD regimen.

SDD had a significant impact on potential Gramnegative pathogen counts in the faecal microbiota to which it is targeted. Enterobacteriaceae in the SDD regimen were significantly reduced in numbers compared to both the SC-regimen and the SOD-regimen.

The gram-positive potential pathogens such as the enterococci increased significantly with the use of SDD, in comparison with both other regimens (Table 4). A significant rise in Enterococcus faecalis was also seen in the SOD regimen compared to the SC regimen. However, the numbers of $E$. faecalis in the SOD regimen were still significantly lower than when compared to the numbers of E. faecalis in the SDD regimen.

The MIC values of $F$. prausnitzii A2-165 for the SDD/ SOD antibiotics were $4 \mu \mathrm{g} / \mathrm{ml}$ for tobramycin, $>32 \mu \mathrm{g} / \mathrm{ml}$ for cefotaxime and $>256 \mu \mathrm{g} / \mathrm{ml}$ for colistin.

\section{Discussion}

The major finding in this study was that the composition of the intestinal microbiota, as evidenced by stool analysis, was affected by the use of SDD: the $F$. prausnitzii group was significantly reduced in numbers in stools of subjects receiving SDD compared to subjects in both other regimens. This finding contrasts with the hypothesis of SDD that anaerobic microbiota would remain unaffected [15].

The group of bacteria detected with the Fprau-probe is one of the predominant bacterial groups in healthy volunteers, representing $10-15 \%$ of the intestinal microbiota on average $[17,23]$. The $F$. prausnitzii group therefore plays an important role in maintaining the colonization resistance, normally protecting the human host from infections. $F$. prausnitzii has also been found to have anti-inflammatory effects which may play a 
Table 3 Numbers and statistical analysis of the main intestinal microbiota groups

\begin{tabular}{|c|c|c|c|c|c|c|}
\hline \multirow[t]{3}{*}{ Variable } & \multicolumn{6}{|l|}{ Regimen: } \\
\hline & \multicolumn{2}{|l|}{$\operatorname{SC}\left(21^{\mathrm{a}}\right)$} & \multicolumn{2}{|l|}{$\operatorname{SOD}\left(19^{\mathrm{a}}\right)$} & \multicolumn{2}{|l|}{$\operatorname{SDD}\left(17^{\mathrm{a}}\right)$} \\
\hline & Mean & $95 \% \mathrm{CI}$ & Mean & $95 \% \mathrm{CI}$ & Mean & $95 \% \mathrm{CI}$ \\
\hline \multicolumn{7}{|l|}{ Probe } \\
\hline Total bacteria & $3.7 \times 10^{9}$ & $2.2 \times 10^{9}-6.2 \times 10^{9}$ & $1.6 \times 10^{9}$ & $7.8 \times 10^{8}-3.4 \times 10^{9}$ & $1.9 \times 10^{9}$ & $8.7 \times 10^{8}-4.3 \times 10^{9}$ \\
\hline Bacteroides & $6.5 \times 10^{8}$ & $3.5 \times 10^{8}-1.2 \times 10^{9}$ & $3.6 \times 10^{8}$ & $1.4 \times 10^{8}-9.5 \times 10^{8}$ & $4.2 \times 10^{8}$ & $2.1 \times 10^{8}-8.1 \times 10^{8}$ \\
\hline E. rectale & $5.1 \times 10^{8}$ & $3.0 \times 10^{8}-8.5 \times 10^{8}$ & $1.4 \times 10^{8}$ & $5.4 \times 10^{7}-3.4 \times 10^{8}$ & $6.2 \times 10^{7}$ & $2.6 \times 10^{7}-1.4 \times 10^{8}$ \\
\hline R. intestinalis ${ }^{\mathrm{b}}$ & $6.8 \times 10^{7}$ & $3.7 \times 10^{7}-1.3 \times 10^{8}$ & $1.8 \times 10^{7}$ & $7.0 \times 10^{6}-4.8 \times 10^{7}$ & $1.1 \times 10^{7}$ & $4.9 \times 10^{6}-2.7 \times 10^{7}$ \\
\hline F. prausnitzii ${ }^{\mathrm{c}}$ & $5.5 \times 10^{7}$ & $2.3 \times 10^{7}-1.3 \times 10^{8}$ & $4.0 \times 10^{7}$ & $1.6 \times 10^{7}-9.9 \times 10^{7}$ & $2.9 \times 10^{6}$ & $1.4 \times 10^{6}-6.0 \times 10^{6}$ \\
\hline Atopobium & $1.3 \times 10^{8}$ & $6.6 \times 10^{7}-2.3 \times 10^{8}$ & $3.5 \times 10^{7}$ & $1.3 \times 10^{7}-9.2 \times 10^{7}$ & $4.2 \times 10^{7}$ & $1.4 \times 10^{7}-1.2 \times 10^{8}$ \\
\hline Bifidobacteria & $4.4 \times 10^{7}$ & $1.6 \times 10^{7}-1.2 \times 10^{8}$ & $1.6 \times 10^{7}$ & $5.4 \times 10^{6}-4.6 \times 10^{7}$ & $5.8 \times 10^{7}$ & $1.8 \times 10^{7}-1.8 \times 10^{8}$ \\
\hline Ruminococci & $2.0 \times 10^{8}$ & $1.3 \times 10^{8}-3.3 \times 10^{8}$ & $8.6 \times 10^{7}$ & $3.8 \times 10^{7}-2.0 \times 10^{8}$ & $7.8 \times 10^{7}$ & $3.1 \times 10^{7}-1.7 \times 10^{8}$ \\
\hline Enterobacteriaceae & $7.2 \times 10^{7}$ & $3.6 \times 10^{7}-1.4 \times 10^{8}$ & $4.8 \times 10^{7}$ & $1.7 \times 10^{7}-1.4 \times 10^{8}$ & $4.1 \times 10^{6}$ & $2.0 \times 10^{6}-8.3 \times 10^{6}$ \\
\hline
\end{tabular}

ANOVA test was used for statistical analysis

a Number of study subjects

b Indicates a significant difference between the SDD and SC regimens only

Table 4 Numbers and statistical analysis of enterococci per gram faeces

\begin{tabular}{lllllll}
\hline & $\mathrm{SC}(n=21)$ & $\mathrm{SOD}(n=19)$ & $\mathrm{SDD}(n=17)$ & $\mathrm{SC}$ vs. SOD & SC vs. SDD $^{\mathrm{a}}$ SOD vs. SDD $^{\mathrm{a}}$ \\
\hline E. faecalis & $2.6 \times 10^{6}$ & $7.6 \times 10^{6}$ & $6.9 \times 10^{7}$ & 0.002 & 0.000 & 0.000 \\
E. faecium & $6.3 \times 10^{6}$ & $9.8 \times 10^{6}$ & $5.4 \times 10^{7}$ & 0.142 & 0.000 & 0.000 \\
\hline
\end{tabular}

${ }^{a}$ Mann-Whitney U-tests, $p$ values

dominant role in the development of Crohn's disease [24].

Furthermore, the $F$. prausnitzii group is considered to provide special health benefit for the human host because of its main fermentation product, butyrate [23, 25]. Butyrate is a short chain fatty acid that is the primary source of energy for the colonocytes [26]. In addition, butyrate promotes the growth of colonocytes, preventing mucosal atrophy. It also appears to lower the risk of malignant transformation of colonocytes in animal models [27]. The optimal concentration of butyrate is not known in vivo, but in vitro cell cultures show a growth arrest at concentrations below $10 \mathrm{mM}$ [26]. In healthy volunteers, butyrate concentrations were also reduced during tube feeding [28], and in a blinded re-analysis of these faecal samples, the reduction of $F$. prausnitzii showed strong correlation with the reduction of butyrate measured in these faecal samples (manuscript submitted).

The $F$. prausnitzii-group of bacteria is difficult to culture in vitro and therefore could not be detected when SDD was first developed. Only culture-based methods were used to asses whether the intestinal microbiota remained intact in the early days of SDD. Therefore, this unintended effect could not have been foreseen when the regimen was first used. The MIC analysis of the SDD/
${ }^{c}$ Indicates a significant difference between SDD and both SC and SOD regimens 
Traditionally, cefotaxime been a component of the SDD regimen $[8,12,30]$. Although cefotaxime has been shown to have a moderate suppressive effect on Enterobacteriaceae [31, 32], we have reasons to believe that the effect of cefotaxime is negligible compared to the effect of the large amounts of non-absorbable antibiotics targeted specifically to Enterobacteriaceae.

Cefotaxime elimination is almost entirely by renal excretion; only $5 \%$ of elimination is by biliary excretion, and the amount of cefotaxime reaching the colon is exceedingly low compared to the amounts of nonresorbable tobramycin and colistin, both active against Enterobacteriaceae. Early studies haven shown that cefotaxime is almost entirely inactivated by faecal enzymes [33]. This is not the case with colistin and tobramycin, which makes it most likely that the effect seen is caused by these antibiotics instead. Furthermore the earlier studies of the effects of cefotaxime on the intestinal microbiota are based upon culturing methods with selective plates. Especially when antibiotics are used, these methods can lead to underestimation of the actual numbers of bacteria.

The second important finding is that SOD left the faecal microbiota relatively unaffected compared to stools from patients enrolled during the SC period of the study. As shown in the multi-center clinical trial [12], there is no significant difference in mortality between SDD and SOD, despite the fact that colonisation and infections with Enterobacteriaceae are significantly reduced in SDD compared to SOD. This reduction of Enterobacteriaceae is confirmed in our study. We speculate that the lack of further mortality reduction is partly explained by the negative effect of SDD on beneficial bacteria of the colonic microbiota. How the loss of these beneficial bacteria, which provide an important source of nutrition for colonocytes, translates into clinically significant effects in general, and in critically ill patients in particular, is presently unknown. The role of microbiota and the production and uptake of butyrate in particular to maintain colonic integrity in a range of conditions, including critical care settings with sepsis, should perhaps be studied in animal models.

The Bifidobacteria showed a mild increase in the SDD regimen that did not reach statistical significance. These Gram-positive bacteria are not susceptible to the antibiotics used in SDD.

A third consideration with the use of SDD is the increase of enterococci in the faeces [34]. Although the numbers of $E$. faecalis are also significantly higher in the SOD regimen compared to the SC regimen, the numbers of enterococci in the SDD regimen are an order of magnitude higher than in both other regimens. It is historically known that enterococci tend to increase in numbers under similar use of topical antibiotics [35], as these Grampositive bacteria are naturally resistant to the SDD-antibiotics. Also, Gram-negative intestinal bacteria induce an antimicrobial peptide, Reg3g, at the luminal surface of intestinal cells by stimulating TLR4 [36], with growth limiting effects on enterococci. Elimination of Gram negative bacteria resulted in a decrease of Reg3g with subsequent increase and translocation of enterococci in a mouse model [36].

The enterococci were considered to be harmless when SDD was first introduced in the ICU and none of the included patients had bloodstream infections with enterococci. However, we are aware that enterococci cause serious nosocomial infections, spread easily, and acquire increased antibiotic resistance [37, 38]. Enterococci are the third leading cause of endocarditis, and nosocomial acquisition is associated with a poor prognosis [39, 40]. Furthermore, antibiotic resistance gene-transfer has been demonstrated in vivo between enterococci and other bacterial species [41].

Limitations to the study are the limited numbers of patients and samples. Also, by design of the study, no baseline samples could be obtained nor could the timing of the sampling be standardized, as all samples were produced spontaneously. Based upon the data provided in table 2 we believe this has not caused a major source of bias.

\section{Conclusion}

We show that the total numbers of bacteria of the faecal microbiota in patients in the ICU are not significantly influenced by SDD. Enterobacteriaceae dropped significantly in numbers in the SDD regimen compared to SC and SOD regimens, as expected.

SDD does have a significant impact on the composition of the anaerobic intestinal microbiota; the number of $F$. prausnitzii-group of bacteria is significantly reduced during the SDD regimen compared to both SC and SOD regimens. The bacteria from the Enterococcus groups are present in significantly higher numbers in the SDD compared to both SC and SOD regimens. The other groups of bacteria show some variations but these are not significant between both other regimens.

The hypothesis that SDD is unequivocally beneficial by only reducing Enterobacteriaceae while leaving the colonic microbiota unaffected has to be rejected.

Acknowledgments R.F.J. Benus has received a grant from 'UMCG Stimuleringsgelden'. We thank M. Tanweer Khan for the culturing of $F$. prausnitzii and performing the MIC-tests.

Open Access This article is distributed under the terms of the Creative Commons Attribution Noncommercial License which permits any noncommercial use, distribution, and reproduction in any medium, provided the original author(s) and source are credited. 


\section{References}

1. van der Waaij D, Berghuis-de Vries JM, Lekkerkerk-van der Wees JE (1971) Colonization resistance of the digestive tract in conventional and antibiotictreated mice. J Hyg (Lond) 69:405-411

2. van der Waaij D (1992) History of recognition and measurement of colonization resistance of the digestive tract as an introduction to selective gastrointestinal decontamination. Epidemiol Infect 109:315-326

3. Stoutenbeek CP, van Saene HK, Miranda DR, Zandstra DF (1984) The effect of selective decontamination of the digestive tract on colonisation and infection rate in multiple trauma patients. Intensive Care Med 10:185192

4. D'Amico R, Pifferi S, Leonetti C, Torri V, Tinazzi A, Liberati A (1998) Effectiveness of antibiotic prophylaxis in critically ill adult patients: systematic review of randomised controlled trials. BMJ 316:1275-1285

5. Liberati A, D'Amico R, Pifferi, Torri V, Brazzi L (2004) Antibiotic prophylaxis to reduce respiratory tract infections and mortality in adults receiving intensive care. Cochrane Database Syst Rev (CD000022)

6. Vandenbroucke-Grauls CM, Vandenbroucke JP (1991) Effect of selective decontamination of the digestive tract on respiratory tract infections and mortality in the intensive care unit. Lancet 338:859-862

7. Krueger WA, Lenhart FP, Neeser G, Ruckdeschel G, Schreckhase H, Eissner HJ, Forst H, Eckart J, Peter K, Unertl KE (2002) Influence of combined intravenous and topical antibiotic prophylaxis on the incidence of infections, organ dysfunctions, and mortality in critically ill surgical patients: a prospective, stratified, randomized, double-blind, placebocontrolled clinical trial. Am J Respir Crit Care Med 166:1029-1037

8. de Jonge E, Schultz MJ, Spanjaard L, Bossuyt PM, Vroom MB, Dankert J, Kesecioglu J (2003) Effects of selective decontamination of digestive tract on mortality and acquisition of resistant bacteria in intensive care: a randomised controlled trial. Lancet 362:1011-1016

9. Bergmans DC, Bonten MJ, Gaillard CA, Paling JC, van der Geest S, van Tiel FH, Beysens AJ, de Leeuw PW, Stobberingh EE (2001) Prevention of ventilator-associated pneumonia by oral decontamination: a prospective, randomized, double-blind, placebocontrolled study. Am J Respir Crit Care Med 164:382-388
10. Liberati A, D'Amico R, Pifferi S, Torri V, Brazzi L, Gensini GF, Gusinu R (2006) Antibiotic prophylaxis to prevent nosocomial infections in patients in intensive care units: evidence that struggle to convince practising clinicians. Intern Emerg Med 1:160-162

11. Koeman M, van der Ven AJ, Hak E, Joore HC, Kaasjager K, de Smet AG, Ramsay G, Dormans TP, Aarts LP, de Bel EE, Hustinx WN, van der Tweel I, Hoepelman AM, Bonten MJ (2006) Oral decontamination with

chlorhexidine reduces the incidence of ventilator-associated pneumonia. Am J Respir Crit Care Med 173:1348-1355

12. de Smet AM, Kluytmans JA, Cooper BS, Mascini EM, Benus RF, van der Werf TS, van der Hoeven JG, Pickkers P, Bogaers-Hofman D, van der Meer NJ, Bernards AT, Kuijper EJ, Joore JC, Leverstein-van Hall MA, Bindels AJ, Jansz AR, Wesselink RM, de Jongh BM, Dennesen PJ, van Asselt GJ, te Velde LF, Frenay IH, Kaasjager K, Bosch FH, van Iterson M, Thijsen SF, Kluge GH, Pauw W, de Vries JW, Kaan JA, Arends JP, Aarts LP, Sturm PD, Harinck HI, Voss A, Uijtendaal EV, Blok HE, Thieme Groen ES, Pouw ME, Kalkman CJ, Bonten MJ (2009) Decontamination of the digestive tract and oropharynx in ICU patients. N Engl J Med 360:20-31

13. Vanhoutte T, Huys G, de Brandt E, Swings J (2004) Temporal stability analysis of the microbiota in human feces by denaturing gradient gel electrophoresis using universal and group-specific 16S rRNA gene primers. FEMS Microbiol Ecol 48:437-446

14. Gibson GR, Roberfroid MB (1995) Dietary modulation of the human colonic microbiota: introducing the concept of prebiotics. J Nutr 125:14011412

15. van der Waaij D, Manson WL, Arends JP, de Vries-Hospers HG (1990) Clinical use of selective decontamination: the concept. Intensive Care Med 16(Suppl 3):S212-S216

16. Harmsen HJ, Gibson GR, Elfferich P, Raangs GC, Wildeboer-Veloo AC, Argaiz A, Roberfroid MB, Welling GW (2000) Comparison of viable cell counts and fluorescence in situ hybridization using specific rRNA-based probes for the quantification of human fecal bacteria. FEMS Microbiol Lett 183:125-129
17. Harmsen HJ, Raangs GC, He T, Degener JE, Welling GW (2002) Extensive set of 16S rRNA-based probes for detection of bacteria in human feces. Appl Environ Microbiol 68:2982-2990

18. Knaus WA, Draper EA, Wagner DP, Zimmerman JE (1985) APACHE II: a severity of disease classification system. Crit Care Med 13:818-829

19. Franks AH, Harmsen HJ, Raangs GC, Jansen GJ, Schut F, Welling GW (1998) Variations of bacterial populations in human feces measured by fluorescent in situ hybridization with group-specific 16S rRNA-targeted oligonucleotide probes. Appl Environ Microbiol 64:3336-3345

20. Poulsen LK, Lan F, Kristensen CS, Hobolth P, Molin S, Krogfelt KA (1994) Spatial distribution of Escherichia coli in the mouse large intestine inferred from rRNA in situ hybridization. Infect Immun 62:51915194

21. Waar K, Degener JE, van Luyn MJ, Harmsen HJ (2005) Fluorescent in situ hybridization with specific DNA probes offers adequate detection of

Enterococcus faecalis and Enterococcus faecium in clinical samples. J Med Microbiol 54:937-944

22. Jansen GJ, Wildeboer-Veloo AC, Tonk RH, Franks AH, Welling GW (1999) Development and validation of an automated, microscopy-based method for enumeration of groups of intestinal bacteria. J Microbiol Methods 37:215221

23. Suau A, Rochet V, Sghir A, Gramet G, Brewaeys S, Sutren M, Rigottier-Gois L, Doré J (2001) Fusobacterium prausnitzii and related species represent a dominant group within the human fecal flora. Syst Appl Microbiol 24:139-145

24. Sokol H, Pigneur B, Watterlot L, Lakhdari O, Bermúdez-Humarán LG, Gratadoux JJ, Blugeon S, Bridonneau C, Furet JP, Corthier G, Grangette C, Vasquez N, Pochart P, Trugnan G, Thomas G, Blottière HM, Doré J, Marteau P, Seksik P, Langella P (2008) Faecalibacterium prausnitzii is an antiinflammatory commensal bacterium identified by gut microbiota analysis of Crohn disease patients. Proc Natl Acad Sci USA 105:16731-16736

25. Duncan SH, Hold GL, Harmsen HJ, Stewart CS, Flint HJ (2002) Growth requirements and fermentation products of Fusobacterium prausnitzii, and a proposal to reclassify it as Faecalibacterium prausnitzii gen. nov., comb. nov. Int J Syst Evol Microbiol 52:2141-2146 
26. Pryde SE, Duncan SH, Hold GL, Stewart CS, Flint HJ (2002) The microbiology of butyrate formation in the human colon. FEMS Microbiol Lett 217:133-139

27. Koruda MJ, Rolandelli RH, Bliss DZ, Hastings J, Rombeau JL, Settle RG (1990) Parenteral nutrition supplemented with short-chain fatty acids: effect on the small-bowel mucosa in normal rats. Am J Clin Nutr 51:685689

28. Whelan K, Judd PA, Preedy VR, Simmering R, Jann A, Taylor MA (2005) Fructooligosaccharides and fiber partially prevent the alterations in fecal microbiota and short-chain fatty acid concentrations caused by standard enteral formula in healthy humans. J Nutr 135:1896-1902

29. Duncan SH, Belenguer A, Holtrop G, Johnstone AM, Flint HJ, Lobley GE (2007) Reduced dietary intake of carbohydrates by obese subjects results in decreased concentrations of butyrate and butyrate-producing bacteria in feces. Appl Environ Microbiol 73:1073-1078

30. van Saene HK, Stoutenbeek CP, Zandstra DF (1988) Cefotaxime combined with selective decontamination in long term intensive care unit patients. Virtual absence of emergence of resistance. Drugs 35 Suppl 2:29-34

31. Vollaard EJ, Clasener HA, Janssen AJ, Wynne HJ (1990) Influence of cefotaxime on microbial colonization resistance in healthy volunteers. J Antimicrob Chemother 26:117-123
32. Guggenbichler JP, Kofler J, Allerberger F (1985) The influence of thirdgeneration cephalosporins on the aerobic intestinal flora. Infection 13(Suppl 1):S137-S139

33. Welling GW, Groen G (1993) Specific inactivation of antimicrobial agents and its interindividual differences. Old Herborn University Seminar Monographs 3. The Institute for Microbiology and Biochemistry, Herborn-Dill, pp 47-54

34. Pultz NJ, Stiefel U, Subramanyan S, Helfand MS, Donskey CJ (2005) Mechanisms by which anaerobic microbiota inhibit the establishment in mice of intestinal colonization by vancomycin-resistant Enterococcus. J Infect Dis 191:949-956

35. Bonten MJ, Gaillard CA, van Tiel FH, van der GS, Stobberingh EE (1995) Colonization and infection with Enterococcus faecalis in intensive care units: the role of antimicrobial agents. Antimicrob Agents Chemother 39:2783-2786

36. Brandl K, Plitas G, Mihu CN, Ubeda C, Jia T, Fleisher M, Schnabl B, DeMatteo RP, Pamer EG (2008) Vancomycinresistant enterococci exploit antibioticinduced innate immune deficits. Nature 455:804-807

37. Montecalvo MA, Horowitz H, Gedris C, Carbonaro C, Tenover FC, Issah A, Cook P, Wormser GP (1994) Outbreak of vancomycin-, ampicillin-, and aminoglycoside-resistant Enterococcus faecium bacteremia in an adult oncology unit. Antimicrob Agents Chemother 38:1363-1367
38. Willems RJ, Top J, van Santen M, Robinson DA, Coque TM, Baquero F, Grundmann H, Bonten MJ (2005) Global spread of vancomycin-resistant Enterococcus faecium from distinct nosocomial genetic complex. Emerg Infect Dis 11:821-828

39. Fernandez Guerrero ML, Goyenechea A, Verdejo C, Roblas RF, de GM (2007) Enterococcal endocarditis on native and prosthetic valves: a review of clinical and prognostic factors with emphasis on hospital-acquired infections as a major determinant of outcome. Medicine (Baltimore) 86:363-377

40. Stevens MP, Edmond MB (2005) Endocarditis due to vancomycinresistant enterococci: case report and review of the literature. Clin Infect Dis 41:1134-1142

41. Netherwood T, Bowden R, Harrison P, O'Donnell AG, Parker DS, Gilbert HJ (1999) Gene transfer in the gastrointestinal tract. Appl Environ Microbiol 65:5139-5141 